\section{Zika Virus Persistence and Higher Viral Loads in Cutaneous Capillaries Than in Venous Blood}

\section{Séverine Matheus, Franck de Laval, David Moua, Christophe N'Guyen, Enguerrane Martinez, Dominique Rousset, Sébastien Briolant}

\begin{abstract}
Author affiliations: Institut Pasteur de la Guyane, Cayenne, French Guiana (S. Matheus, D. Moua, D. Rousset); Military Centre for Epidemiology and Public Health, Marseille, France (F. de Laval); French Armed Forces Health Service, Cayenne (F. de Laval, E. Martinez); French Armed Forces Biomedical Research Institute, Marseille (C. N'Guyen, S. Briolant)
\end{abstract}

DOI: https://doi.org/10.3201/eid2311.170337

We collected venous and capillary serum samples from 21 Zika virus-infected patients on multiple days after symptom onset and found RNA load was higher and median duration of virus detection significantly longer in capillary than in venous blood. These findings raise questions about the role of the capillary compartment in virus transmission dynamics.

$\mathrm{Z}$ ika virus, belonging to the family Flaviviridae and genus Flavivirus, is transmitted to humans by mosquito bites but can also be contracted through sexual and vertical transmission (1). Zika virus was first detected in Brazil in 2015 and has since spread with the same speed as chikungunya virus through South and Central America and the Caribbean Islands, despite a shorter and lower viremia in humans and a longer replication period in the vector $(2,3)$. As with other arboviruses, Zika virus viremia is commonly measured in venous blood, even though mosquitoes introduce virus into cutaneous capillary blood. We conducted a prospective descriptive study with Zika virus patients during the Zika virus epidemic in French Guiana to evaluate the kinetics of Zika virus RNA load in serum samples collected sequentially from venous and skin capillary blood.

The study population comprised 21 symptomatic and consenting Zika virus patients infected during March-September 2016. We confirmed Zika virus infection by realtime reverse transcription PCR (RT-PCR) of serum and urine samples provided by patients during the first few days after symptom onset. We obtained serum samples from the venous and cutaneous capillary blood (collected from the fingertip) sequentially $1-18$ days after the onset of symptoms. The median age of the population was 40 (range 28-63) years and the sex ratio (male:female) was 1.6. We observed no co-morbidities, and all participants were found to be free of dengue and chikungunya virus infections by methods previously described $(4,5)$.

We extracted RNA from $150-\mu \mathrm{L}$ samples using the QIAamp Viral RNA kit (QIAGEN, Hilden, Germany) and performed Zika virus RNA amplification using the RealStar Zika Virus RT-PCR Kit 1.0 (Altona Diagnostics $\mathrm{GmbH}$, Hamburg, Germany) according to the manufacturer's instructions. We performed Zika virus RNA quantification using a reference strain provided by the European Zika Virus Archive (SKU no. 001N-01648) and estimated the Zika virus RNA load as $\log _{10}$ copies per milliliter (online Technical Appendix Table, https://wwwnc.cdc.gov/EID/ article/23/11/17-0337-Techapp1.pdf).

Zika virus RNA loads in capillary blood correlated with those in venous blood (Spearman correlation test, $r=0.54, \mathrm{p}<0.0001)$ but were significantly higher in the capillary samples (Wilcoxon signed rank test, $\mathrm{p}=0.0003$ ), except for 3 patients (nos. 2, 13, and 21; online Technical Appendix Table). The median duration of Zika virus detection after symptom onset was significantly greater in capillary blood than in venous blood ( $\mathrm{p}=0.005$ by $\log$ rank test; hazard ratio $=2.99,95 \%$ CI $1.39-6.43$ ), even though the duration of detection in capillary blood was underestimated; RNA was still detectable in the last capillary blood samples taken from 8 patients (nos. 1, 5, 6, 8, 11, 15, 16, and 19; online Technical Appendix Table). The duration of Zika virus RNA detection was greater in capillary than in venous blood for $12(57 \%, 95 \%$ CI $34 \%-78 \%)$ of the 21 patients (nos. 1, 3, 5, 6, 7, 8, 11, 14, 15, 16, 19, and 20). The maximum duration of RNA detection in capillary blood samples was 18 days after the onset of symptoms (seen with patient no. 19) with a load of $1.9 \log _{10}$ copies $/ \mathrm{mL}$. The duration of detection was equal between the 2 compartments for 7 $(33 \%, 95 \%$ CI $15 \%-57 \%)$ of 21 patients (nos. $4,9,10,12$, $13,17$, and 18$)$ and longer in venous blood for $2(10 \%, 95 \%$ CI 1\%-30\%) of 21 patients (nos. 2 and 21) (online Technical Appendix Table).

These data raise questions about the consequences of longer persistence and higher loads of Zika virus RNA in the cutaneous capillary blood compartment, although we did not test Zika virus replication capacity. The higher load and longer detection of Zika virus RNA in this compartment might be attributable to Zika virus replication in permissive cells of the skin (e.g., human dermal fibroblasts and epidermal keratinocytes); capillaries; or both (6). If the Zika virus RNA observed in the serum samples taken from the capillary compartment reflects the presence of infectious virus particles, symptomatic Zika virus-infected patients would need to be shielded from mosquitoes for a longer period than is currently practiced to limit potential vectorborne transmission.

This study comparing the kinetics of Zika virus RNA load between the venous and capillary compartments 
highlights the need to further investigate the infectivity and pathophysiology of the virus located in the often neglected capillary compartment. These findings provide new information on this biologic compartment, which plays a key role in vectorborne transmission and transmission dynamics. Moreover, these observations, if validated with more patients and extended to other vectorborne infections, will be vital for preventing and controlling the transmission of Zika virus and other arboviruses.

Institutional review board approval was granted by the Comité de Protection des Personnes Sud-Méditerranée I corresponding to the following study "Etude descriptive prospective de la maladie à virus Zika au sein de la communauté de défense des Forces Armées en Guyane" and was registered February 2016 under the number RCB: 2016-A00394-47. Written informed consent was obtained from each patient as required by the Comité de Protection des Personnes Sud-Méditerranée I.

This work was funded by the Direction Centrale du Service de Santé des Armées (grant agreement 2016RC10) and supported by the European Virus Archive Goes Global project, which has received funding (grant agreement 653316) from the European Union's Horizon 2020 Research and Innovation Program. Funding sources played no role in study design, patient recruitment, data collection, analysis and interpretation of the data, or writing of the manuscript or the decision to submit it for publication.

Dr. Matheus is a research assistant at the Institute Pasteur de la Guyane, French Guiana, with research interests in the diagnosis and pathophysiology of arboviruses. She is currently studying viral emergence, particularly that of a hantavirus in French Guiana.

\section{References}

1. Petersen LR, Jamieson DJ, Honein MA. Zika virus. N Engl J Med. 2016;375:294-5.

2. Waggoner JJ, Gresh L, Vargas MJ, Ballesteros G, Tellez Y, Soda KJ, et al. Viremia and clinical presentation in Nicaraguan patients infected with Zika virus, chikungunya virus, and dengue virus. Clin Infect Dis. 2016;63:1584-90. http://dx.doi.org/10.1093/cid/ciw589

3. Chouin-Carneiro T, Vega-Rua A, Vazeille M, Yebakima A, Girod R, Goindin D, et al. Differential susceptibilities of Aedes aegypti and Aedes albopictus from the Americas to Zika virus. PLoS Negl Trop Dis. 2016;10:e0004543. http://dx.doi.org/10.1371/ journal.pntd.0004543

4. Callahan JD, Wu SJ, Dion-Schultz A, Mangold BE, Peruski LF, Watts DM, et al. Development and evaluation of serotype- and group-specific fluorogenic reverse transcriptase PCR (TaqMan) assays for dengue virus. J Clin Microbiol. 2001;39:4119-24. http://dx.doi.org/10.1128/JCM.39.11.4119-4124.2001

5. Panning M, Grywna K, van Esbroeck M, Emmerich P, Drosten C. Chikungunya fever in travelers returning to Europe from the Indian Ocean region, 2006. Emerg Infect Dis. 2008;14:416-22. http://dx.doi.org/10.3201/eid1403.070906

6. Hamel R, Dejarnac O, Wichit S, Ekchariyawat P, Neyret A, Luplertlop N, et al. Biology of Zika virus infection in human skin cells. J Virol. 2015;89:8880-96. http://dx.doi.org/10.1128/ JVI.00354-15
Address for correspondence: Séverine Matheus, Institut Pasteur de la Guyane, Centre National de Référence des Arbovirus, laboratoire associé, 23 ave Pasteur, BP 6010-97306 Cayenne CEDEX, French Guiana; email: smatheus@pasteur-cayenne.fr

\section{Detection of Spotted Fever Group Rickettsia DNA by Deep Sequencing}

\author{
Rikki M.A. Graham, Steven Donohue, \\ Jamie McMahon, Amy V. Jennison
}

Author affiliations: Queensland Department of Health, Coopers Plains, Queensland, Australia (R.M.A. Graham, J. McMahon, A.V. Jennison); Townsville Public Health Unit, Townsville, Queensland, Australia (S. Donohue)

DOI: https://doi.org/10.3201/eid2311.170474

After conventional molecular and serologic testing failed to diagnose the cause of illness, deep sequencing identified spotted fever group Rickettsia DNA in a patient's blood sample. Sequences belonged to $R$. honei, the causative agent of Flinders Island spotted fever. Next-generation sequencing is proving to be a useful tool for clinical diagnostics.

$\mathrm{W}$ hen conventional laboratory tests cannot identify an etiologic agent, unbiased deep sequencing performed directly on a clinical sample has the potential to identify a probable cause of disease. We used deep sequencing to detect spotted fever group (SFG) Rickettsia DNA in the blood of a patient for whom diagnosis was not possible through conventional molecular and serologic testing.

In late 2016, a middle-aged woman was admitted to a regional hospital in Queensland, Australia, after 2 weeks of mild cough, myalgia, fever, and lethargy. The day before admission, she experienced a blanching rash and pains in her feet, after which her condition deteriorated and a definite petechial rash appeared. Chest radiographs showed atelectasis on 1 side. Meningococcal septicemia was suspected, and the patient was transferred to intensive care with septic shock. Despite treatment with inotropes and several antimicrobial drugs (including ceftriaxone, vancomycin, meropenem, doxycycline), the patient died the next morning.

Clinical testing did not identify an infectious disease agent in the patient's blood; serologic test results 